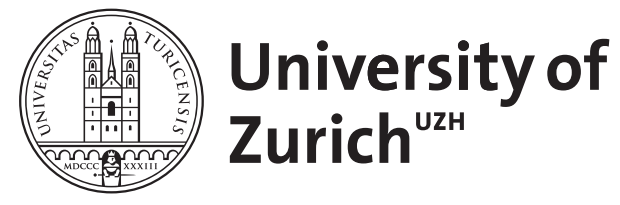
Archive

University of Zurich

University Library

Strickhofstrasse 39

CH-8057 Zurich

www.zora.uzh.ch

Year: 1991

\title{
Diagnostic identification of Taenia saginata with the polymerase chain reaction
}

\author{
Gottstein, B ; Deplazes, P ; Tanner, I ; Skaggs, J S
}

DOI: https://doi.org/10.1016/0035-9203(91)90042-w

Posted at the Zurich Open Repository and Archive, University of Zurich ZORA URL: https://doi.org/10.5167/uzh-154288

Journal Article

Published Version

Originally published at:

Gottstein, B; Deplazes, P; Tanner, I; Skaggs, J S (1991). Diagnostic identification of Taenia saginata with the polymerase chain reaction. Transactions of the Royal Society of Tropical Medicine and Hygiene, 85(2):248-249.

DOI: https://doi.org/10.1016/0035-9203(91)90042-w 


\section{Short Report}

\section{Diagnostic identification of Taenia saginata with the polymerase chain reaction}

\author{
B. Gottstein, P. Deplazes, I. Tanner and J. S. \\ Skaggs Institute of Parasitology, University of Zürich, \\ Switzerland
}

Taeniasis of human patients in central Europe is mainly caused by intestinal infection with the adult stage of Taenia saginata. This tapeworm is of economic and veterinary importance because of its larval infection of bovine intermediate hosts (=bovine cysticercosis). As an example, 2 cattle-breeding Swiss farmers were recently reporting annual losses of 10000 and $40000 \mathrm{SFr}$, respectively, due to infected beef confiscated at meat inspection. Reliable and very sensitive immunodiagnostic techniques have been developed for various Taenia spp., based on the detection of copro-antigens by enzyme-linked immunosorbent assay in human stool specimens; such tests proved to be diagnostically more sensitive than classical faecal examination (DEPLAZES et al., 1990). However, these immunodiagnostic techniques operate at the genus level and thus do not allow discrimination of hurnans infected with $T$. saginata from those infected with $T$, solium, the latter causing systemic human larval (neuro-)cysticercosis. Both parasite species are diagnosed with increasing frequency among various immigrant ethnic groups in Switzerland, as well as among persons frequently travelling to endemic areas. Specific morphological identification of $T$. saginata and $T$. solium proglottids originating from diagnostic stool specimens is often difficult and mainly dependent upon full maturity and morphological integrity of the parasite segments. These requirements are often not fulfilled as the parasites are morphologically damaged by chemotherapy given to patients after an initial diagnosis based on the detection of taeniid eggs. Morphological identification or discrimination of taeniid eggs is not possible. In consequence, deoxyribonucleic acid (DNA) probes have recently been developed which allow differentiation of genomic DNA of the tapeworm species by Southern hybridization techniques (FLISSER et al., 1988; HARRISON et al., 1990). Such procedures are technically not suitable for rapid routine diagnostic investigations. Furthermore, identification of small numbers of taeniid eggs (e.g., from 'Scotch-tape' samples) may result in marked problems of sensitivity. In these respects we have demonstrated that the polymerase chain reaction (PCR) was ideal for discriminating at the genomic level between various Echinococcus and Taenia species (GOTTSTEIN \& MOWATT, 1991). In the course of evaluating this

Correspondence to Dr B. Gottstein, Institute of Parasitology, University of Zürich, Winterthurerstrasse 266a, $\mathrm{CH}$ 8057 Zürich, Switzerland.
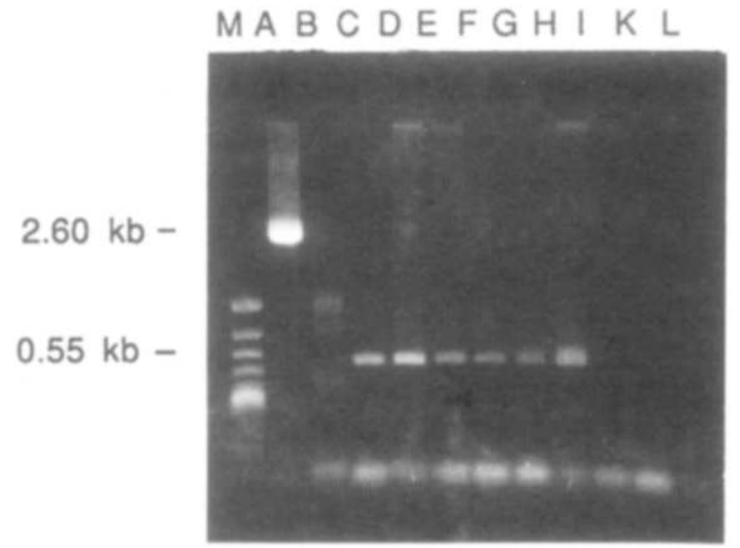

Figure. Photograph of gel stained with ethidium bromide, showing electrophoretically resolved polymerase chain reaction products. DNA templates were prepared from the following parasite species: Echinococcus multilocularis, intertest positive control (A); E. granulosus, intertest negative control (B); Taenia saginata, cysticercus positive control (C); T. saginata, diagnostic samples from 5 different patients (D-H); T. solium, two isolates (I, K); Hymenolepis diminuta, negative control DNA template (L); $\phi 174$ molecular weight markers ( $\mathrm{M} ; \mathrm{kb}=$ kilobase).

diagnostic PCR we observed the amplification of a 0.55 kilobase (kb) DNA fragment which could be attributed uniquely to $T$. saginata genomic template DNA, in contrast to an $E$. multilocularis speciesspecific $2.6 \mathrm{~kb}$ fragment defined by the same oligonucleotide primer sets (BG1 and BG2 primers).

We obtained tapeworm proglottids for diagnostic identification of the cestode species from 5 patients originating from geographical areas where $T$. solium has never been reported. After parasitological identification, a single proglottid or a fraction of it (independent of its morphological appearance) from each patient was used to extract genomic DNA as described elsewhere (GoTTSTEIN \& MOWATT, 1991), which was subsequently amplified by PCR. Electrophoretic analysis of PCR products showed that all $T$. saginata DNA templates (including the control $T$. saginata DNA obtained from bovine $T$. saginata cysticerci) resulted reliably in a $0.55 \mathrm{~kb}$ PCR product. $T$. solium template DNA from isolates from 2 geographically disparate areas (South Africa and Mexico) did not show this product, thus confirming the discriminating specificity of the reaction suggested by GotTsTEIN \& MOWATT (1991). The diagnostic sensitivity of PCR had been calculated in the previous investigation (GOTTSTEIN \& MOWATT, 1991) to reach a lower limit of single egg identification. DNA amplification hence provides a highly sensitive, specific and easy technique for identification of $T$. saginata proglottids, eggs or cysticerci. Its application in routine diagnosis is established in our laboratory and we suggest that it be used for epidemiological and control studies.

References

Deplazes, P., Gottstein, B., Stingelin, Y. \& Eckert, J. (1990). Detection of Taenia hydatigena copro-antigens by ELISA in dogs. Veterinary Parasitology, 36, 91-103. 
Flisser, A., Reid, A., Garcia-Zepeda, E. \& McManus, D. P. (1988). Specific detection of Taenia saginata eggs by DNA hybridization. Lancet, ii, 1429-1430.

Gottstein, B. \& Mowatt, M. R. (1991). Sequencing and characterization of an Echinococcus multilocularis DNA probe and its use in the polymerase chain reaction (PCR). Molecular and Biochemical Parasitology, 44, 183-194.
Harrison, L. J. S., Delgado, J. \& Parkhouse, R. M. E. (1990). Differential diagnosis of Taenia saginata and Taenia solium with DNA probes. Parasitology, 100, 459-461.

Received 15 November 1990; accepted for publication 19 December 1990

\section{Short Report}

\section{Prevalence of Enterobius vermicularis in man in Malaysia}

\author{
Wahab A. Rahman School of Biological Sciences, \\ University of Science Malaysia, Penang 11800, \\ Malaysia
}

Enterobius vermicularis is a common helminth parasite of man in Malaysia. However, despite its potential public health significance, there is no published report of its prevalence in Malaysia and the present investigation was carried out to establish this.

The study area, adjacent to the campus of the University of Science in the city of Penang, Malaysia, is a middle-class residential housing estate consisting of some 300 dwellings. Samples were collected from 317 inhabitants in the area for 5 consecutive days using the Scotch-tape technique. The inhabitants were advised to obtain the samples as soon as they woke and before defecating or washing every morning. All samples were stored at $4^{\circ} \mathrm{C}$ before examination of the slides for $E$. vermicularis eggs. When any of the 5 slides from an individual was found to contain eggs, he or she was considered infected with the parasite. The results are shown in the Table.

Usually the migrating Enterobius and the deposited eggs cause pruritis in the perineum, although there have been reports of the parasite being found in the prostate and vagina (MARSDEN, 1960; BAK et al., 1982). Our results indicate that there was a significantly high prevalence in children aged 1-10 years. These young children are probably not aware of, and not so concerned with, their personal health as are older children and adults. Although the presence of
Table. Presence of Enterobius eggs

\begin{tabular}{lcc}
\hline Age (years) & No. examined & No. positive \\
\hline $1-10$ & 64 & $37(57 \cdot 8 \%)$ \\
$11-20$ & 72 & $28(38 \cdot 9 \%)$ \\
$21-30$ & 78 & $12(15 \cdot 4 \%)$ \\
$30-40$ & 60 & $11(18 \cdot 3 \%)$ \\
$>40$ & 43 & $9(20 \cdot 9 \%)$ \\
\hline Total & 317 & $97(30 \cdot 6 \%)$
\end{tabular}

the worms in these young children is of no clinical significance, complaints of discomfort and sleeplessness have been reported by their parents, causing much distress to the family. In Singapore, KAN et al. (1971) also reported a high prevalence in children aged around 10 years.

In Malaysia, as elsewhere, the major problem with $E$. vermicularis is reinfection. Control can be achieved only by personal hygiene, which needs to be emphasized, especially to young children, who are more prone to infection. Once a family member is found to be infected the entire family should be treated immediately.

\section{References}

Bak, M., Bak, M., Ir \& Bodo, M. (1982). Vaginal enterobiasis. Acta Cytologia, 26, 264-265.

Kan, S. P., Siak, C. L. \& Mulkit, S. (1971). Prevalence of enterobiasis in children admitted to a hospital in Singapore. Annals of Tropical Medicine and Parasitology, $65,81-83$.

Marsden, A. T. H. (1960). Report of a nematode worm, probably Enterobius vermicularis, in the prostate. Medical Journal of Malaysia, 14, 187-190.

Received 30 August 1990; accepted for publication 9 November 1990 